\title{
Beneficial Effects of Lemon Balm Leaf Extract on In Vitro Glycation of Proteins, Arterial Stiffness, and Skin Elasticity in Healthy Adults
}

\author{
Shintaro YuI, Suzuka FujIWARA, Katsuhisa HaradA, Mahoko MotoIKe-HAMURA, \\ Masashi SAKAI, Satoshi MATSUBARA* and Kouji MiYAZAKI \\ Yakult Central Institute, 5-11 Izumi, Kunitachi, Tokyo 186-8650, Japan \\ (Received June 27, 2016)
}

\begin{abstract}
Summary Glycation, a non-enzymatic glycosylation of proteins, induces tissue damage in association with various diseases and aging phenomena. Pentosidine, an advanced glycation end product, is involved in aging phenomena such as tissue stiffness. In this study, we aimed to find a potent anti-glycation food material and to verify its health benefits by clinical trial. From among 681 hot water plant extracts, lemon balm (Melissa officinalis; LB) leaf extract was selected and revealed to have more potent inhibitory activity for pentosidine formation than a representative anti-glycation agent, aminoguanidine. Rosmarinic acid (RA), a typical polyphenol in Lamiaceae plants, was identified as a major active component in LB extract (LBE). Furthermore, LBE or RA dose-dependently suppressed glycation-associated reactions such as increased fluorescence, yellowing of collagen fiber sheets, and degeneration of the fibrous structure of elastin fiber sheets. An open-label, parallel-group comparative trial was conducted in 28 healthy Japanese subjects aged 31-65 y who consumed LB tea (LB group) or barley tea (Control group) for $6 \mathrm{wk}$. The LB group showed significant reductions in brachial-ankle pulse wave velocity, reflecting arterial stiffness, and $b^{*}$ (yellow) color values in forearm skin compared with the Control group. A gender-stratified analysis revealed that cheek skin elasticity was significantly improved in the LB group compared with the Control group only in female subjects. It is concluded that the hot water extract of LB leaf has the potential to provide health benefits with regard to glycation-associated tissue damage in blood vessels and skin of healthy adults.
\end{abstract}

Key Words lemon balm, glycation, pentosidine, arterial stiffness, skin elasticity

Glycation, the non-enzymatic glycosylation of proteins, is known to be involved in the onset of various diseases and conditions of aging. The substances generated by this reaction are known as advanced glycation endproducts (AGEs). Since the tissue contents of AGEs in diabetic patients $(1,2)$ and diabetic animals (3) are known to be much higher than in their healthy counterparts, AGEs are considered to be involved in the progression of complications of diabetes such as diabetic nephropathy (4) and cataracts (5). Involvement of the accumulation of AGEs in cardiovascular diseases $(6,7)$ and Alzheimer's disease $(8)$ has also been reported.

However, the stiffness of tissues such as arteries and skin is known to increase with age $(9,10)$ and is especially high in patients with diabetes compared to healthy subjects $(9,11)$. Pentosidine, one of the crosslinking AGEs, has a structure in which the lysine and arginine residues of tissue protein are cross-linked by a pentose such as ribose (12). It has been reported that pentosidine content increases with age $(2,9,12)$ and positively correlates with the degree of tissue stiffness $(7,13,14)$. One of the causes of the deterioration of tissue elasticity in elderly or diabetic patients is considered to be the accumulation of crosslinking AGEs such as pentosidine $(7,12)$, which generates an intermolecular cross-linked

\footnotetext{
*To whom correspondence should be addressed.

E-mail: satoshi-matsubara@yakult.co.jp
}

structure in extracellular proteins, such as collagen and elastin, which are abundant in blood vessels and skin.

The detailed effects of glycation on the structure of elastin and collagen fibers in vivo have not yet been fully clarified; however, degeneration and weakening of glycated artificial elastin fibers in vitro have been reported (15). In addition, increases in yellowish deposits in the glycated protein have been reported (16), suggesting that yellowing skin with aging might be based partly on glycation (17). Thus materials with anti-glycation activity are expected to be candidates for functional foods with health benefits with regard to glycation-associated tissue damage and symptoms in blood vessels and skin.

In this study, we aimed to identify plant extracts with potent inhibition of pentosidine formation. We also identified active components in lemon balm (Melissa officinalis; LB), the selected extract, and evaluated the effects on glycation-associated reactions in collagen and elastin fiber sheets. Finally, we verified the beneficial effects of LB on arterial stiffness, skin conditions, and blood hematological and biochemical parameters in an open-label, parallel-group comparative trial. Although beneficial effects on cognitive function in clinical trials (18) and psychological stress in an animal model (19) have been previously reported as physiological activities of $\mathrm{LB}$ oral intake, this is the first human trial to examine the influence of LB intake on blood vessels and skin. 


\section{MATERIALS AND METHODS}

In vitro studies

Materials. The following materials were purchased: D-fructose, L-lysine hydrochloride, and L-arginine hydrochloride (Wako Pure Chemical Industries, Ltd., Osaka, Japan), D-ribose (Nacalai Tesque, Inc., Kyoto, Japan), pentosidine (Fushimi Pharmaceutical Co., Ltd., Kagawa, Japan), aminoguanidine hydrochloride (AG), rosmarinic acid (RA) and caffeic acid (Sigma-Aldrich Japan, Tokyo, Japan), salvianic acid A (Carbosynth Ltd., Compton, UK), glutaraldehyde (Merck Millipore, Billerica, MA), collagen fiber sheets (Nippi, Inc., Tokyo, Japan), and elastin fiber sheets (Extra Cellular Matrix Laboratories Ltd., Mie, Japan). Melitric acid A was isolated from the LB leaf extract (LBE) using the high performance liquid chromatography (HPLC) methodology described below, and the purity was determined as $61.1 \%$ by quantitative-nuclear magnetic resonance (NMR) (20).

Preparation of plant extracts. A total of 681 plant extracts were prepared for screening by boiling in 20 times the volume of deionized water $(\mathrm{w} / \mathrm{v})$ at $90^{\circ} \mathrm{C}$ for $30 \mathrm{~min}$. Extracts were then filtered with sterilized gauze, lyophilized, and powdered.

Anti-glycation activity. First, anti-glycation activity was assayed according to the in vitro bovine serum albumin-fructose model reported by Yamaguchi et al. (21) with some modifications. The selected candidate samples were subjected to a pentosidine inhibition assay using an HPLC system (Alliance 2695, Waters, MA), and the half maximal inhibitory concentration $\left(\mathrm{IC}_{50}\right)$ was calculated from the dose-dependent curve. The sample solutions were prepared by dissolving the lyophilized samples in distilled water, and incubated with a mixture of $10 \mathrm{~mm}$ L-lysine, $10 \mathrm{~mm}$ L-arginine, and $10 \mathrm{~mm}$ ribose in $20 \mathrm{~mm}$ phosphate buffer (pH 7.4) at $60^{\circ} \mathrm{C}$ for $24 \mathrm{~h}$. AG solution was used as a positive control. The HPLC analysis was carried out using a TSK-GEL ODS-80TM column (4.6 mm i.d. $\times 150 \mathrm{~mm}, 5 \mu \mathrm{m}$ ) (Tosoh Corp., Tokyo, Japan) at $40^{\circ} \mathrm{C}$, eluted with $3 \%$ acetonitrile in $0.1 \%$ trifluoroacetic acid solution at a flow rate of $1.0 \mathrm{~mL} / \mathrm{min}$. The fluorescence intensity was monitored at an excitation wavelength (Ex) of $305 \mathrm{~nm}$ and emission wavelength (Em) of $370 \mathrm{~nm}$ (RF-535 fluorescent detector; Shimadzu Corp., Kyoto, Japan). The inhibition rate for pentosidine formation was calculated according to the following formula.

Inhibition rate $(\%)=\left(\mathrm{PENT}_{[\mathrm{V}]}-\mathrm{PENT}_{[\mathrm{S}]}\right) / \mathrm{PENT}_{[\mathrm{V}]} \times 100$, where $\mathrm{PENT}_{[\mathrm{V}]}$ is the pentosidine concentration in the reactant with vehicle, and $\mathrm{PENT}_{[\mathrm{S}]}$ is the pentosidine concentration in the reactant with sample solution.

Identification and quantification of active components. Active components in the LBE were identified using HPLC (Alliance 2695), liquid chromatography/mass spectrometry (LC/MS) (Alliance 2695/ZQ 4000; Waters) and NMR (JNM-ECA500; JEOL Ltd., Tokyo, Japan). Their contents in the extract were quantified using an HPLC system with an Ascentis RP-Amide column (4.6 mm i.d. $\times 150 \mathrm{~mm}, 5 \mu \mathrm{m})\left(\right.$ Supelco, Bellefonte, PA) at $35^{\circ} \mathrm{C}$, eluted with the following linear gradient conditions with solvents $\mathrm{A}$ and $\mathrm{B}$ at a flow rate of $1.0 \mathrm{~mL} / \mathrm{min}$, and monitoring at $280 \mathrm{~nm}$ (2996 photo diode array detector; Waters). Solvent A was $0.1 \%$ formic acid solution, and solvent B was acetonitrile. After an initial hold of $5 \mathrm{~min}$, the percentage of solvent B was increased linearly from $9 \%$ to $40 \%$ over $12 \mathrm{~min}$, from $40 \%$ to $80 \%$ over $3 \mathrm{~min}$, from $80 \%$ to $95 \%$ over $3 \mathrm{~min}$ (total run time $23 \mathrm{~min}$ ), and then back to the initial condition of $9 \%$.

Evaluation of the glycation-induced changes in the fibrous structure of elastin fiber sheets. Elastin fiber sheets were incubated with a mixture of $0.05 \mathrm{M}$ ribose and test sample in $100 \mathrm{~mm}$ phosphate buffer $\left(\mathrm{pH} \mathrm{7.4)}\right.$ at $37^{\circ} \mathrm{C}$ for $2 \mathrm{wk}$. The incubated sheets were fixed with $2.5 \%$ glutaraldehyde and dried using a critical point drying system (Leica EM CPD300; Leica Microsystems Japan, Tokyo, Japan). The dried sheets were coated with osmium using an osmium plasma coater (HPC-20; Vacuum Device Ltd., Ibaraki, Japan) and observed at $5 \mathrm{kV}$ accelerating voltage using a scanning electron microscope (SEM) (JSM-6000 NeoScope ${ }^{\text {TM}}$; JEOL Ltd.). To evaluate the curvature in the SEM images, the arc length and chord length of each elastin fiber were measured using a BZ Analyzer (Keyence Corp., Osaka, Japan) (22). The curvature value was defined as: (arc length-chord length)/ chord length. To calculate the curvature values, 20 fibers were randomly selected from each SEM image and analyzed under blind conditions. A portion of the incubated sheet was lyophilized, then lysed in $0.1 \mathrm{~N} \mathrm{NaOH}$ at $95^{\circ} \mathrm{C}$, and the fluorescence intensity of the lysate (Ex $370 \mathrm{~nm} / \mathrm{Em} 440 \mathrm{~nm}$ ) was measured using a fluorescence microplate reader $\left(\right.$ SpectraMax $^{\circledR}$ Gemini; Nihon Molecular Devices Co., Ltd., Tokyo, Japan) to determine the amount of AGEs.

Evaluation of the glycation-induced coloration of collagen fiber sheets. Collagen fiber sheets were incubated with a mixture of $0.4 \mathrm{M}$ ribose and the test sample in $100 \mathrm{~mm}$ phosphate buffer $(\mathrm{pH} \mathrm{7.4})$ at $37^{\circ} \mathrm{C}$ for $1 \mathrm{wk}$. The incubated sheets were decolorized with $100 \mathrm{~mm}$ $\mathrm{HCl} /$ acetone solution at $25^{\circ} \mathrm{C}$ for $30 \mathrm{~min}$ to remove the colored material derived from the test sample. Then, $\mathrm{a}^{*}$ (red), b* (yellow), and $\mathrm{L}^{*}$ (brightness) color values were measured using a spectrophotometer (CM-2600d; Konica Minolta, Tokyo, Japan). The fluorescence intensity of the sheet lysate was measured by the same method as that used for the elastin fiber sheet.

Clinical trial

Subjects. This trial was approved by the Ethics Committee of Yakult Central Institute (No. 114 in 2010) and performed in compliance with the principles of the Declaration of Helsinki. Before enrollment, the purpose and methods of the trial were explained to the subjects, and written informed consent was obtained. Twenty-eight healthy Japanese subjects (14 males and 14 females) aged 31-64 y were enrolled. Exclusion criteria were; i) age under 29 y; ii) use of antihypertensive, cholesterollowering, or anti-diabetes agents, or thyroid hormones; iii) pregnancy or desire to become pregnant; and iv) lactation. During the trial, subjects complied with the dietary restrictions to avoid the intake of herbal teas and herbal supplements other than the designated sample 
tea, with no changes in their lifestyles with regard to diet and exercise.

Test beverages. Test beverages were prepared daily by subjects themselves as follows. First, $3.3 \mathrm{~g}$ dried LB leaves (Charis Seijyo Co., Ltd., Tokyo, Japan) or barley tea grains (Nihon Seibaku Co., Ltd., Kanagawa, Japan) were packed in non-woven fabric bags and extracted for $5 \mathrm{~min}$ in $200 \mathrm{~mL}$ hot water (about $95^{\circ} \mathrm{C}$ ), then the tea was drunk. Table 1 shows the compositions of these test beverages. The measurements of nutrient components were carried out by Japan Food Research Laboratories (Tokyo, Japan). Total polyphenols were evaluated by the ferrous tartrate method (23). The results were expressed as gallic acid equivalent. RA was quantified by the HPLC method described above.

Protocol. An open-label, parallel-group comparative

Table 1. Compositions of the test beverages (/100 g).

\begin{tabular}{lcc}
\hline & Barley tea & LB tea \\
\hline Energy (kcal) & 0 & 2 \\
Protein (g) & $<0.1$ & $<0.1$ \\
Fat (g) & $<0.1$ & $<0.1$ \\
Carbohydrate $(\mathrm{g})$ & 0.1 & 0.5 \\
Dietary fiber $(\mathrm{g})$ & $<0.1$ & $<0.1$ \\
Ash (g) & $<0.1$ & $<0.1$ \\
Sodium (mg) & $<1.0$ & $<1.0$ \\
Vitamin C (mg) & $<1.0$ & $<1.0$ \\
Total polyphenols (mg) & 1.17 & 84.5 \\
RA (mg) & 0 & 61.9
\end{tabular}

Total polyphenols were evaluated by the ferrous tartrate method (23). The results were expressed as gallic acid equivalent. RA was quantified by the HPLC method described in context. trial was conducted from late October to early December in 2010. The test period was composed of the pre-intake period of $1 \mathrm{wk}$ and the intake period of $6 \mathrm{wk}$. Brachialankle pulse wave velocity (baPWV), blood pressure, skin elasticity, skin color, and hematological and biochemical parameters in the pre-intake period were measured (baseline data). The subjects were randomly allocated to the LB group drinking LB tea and Control group drinking barley tea ( $n=14$ in each group) by a researcher who was not involved in the measurement or statistical analysis of this study. There was no bias in terms of sex, age, body weight, baPWV, systolic blood pressure, or diastolic blood pressure. During the 6-wk intake period, the subjects ingested $200 \mathrm{~mL}$ of the designated sample tea once a day (no specified time). The baPWV, blood pressure, skin elasticity, skin color, and blood parameters on the day after the last day of the intake period were also measured.

Diary. During the trial, the daily intake of test beverage and any adverse events were recorded in a diary by subjects every day, in order to check the compliance rate of intake and evaluate the adverse effects. Medications, hospital visits, and alcohol intakes were also recorded in the diary by subjects.

Measurements. After resting for $15 \mathrm{~min}$ in the examination room under constant temperature $\left(25 \pm 1^{\circ} \mathrm{C}\right)$ and humidity $(50 \pm 5 \%)$, baPWV and brachial blood pressure were measured using Form PWV/ABI (Colin Corp., Tokyo, Japan).

The skin elasticity of the left cheek was measured using Cutometer ${ }^{\circledR}$ MPA 580 (Courage and Khazaka Electronic GmbH, Cologne, Germany), equipped with a hand-held probe of $6 \mathrm{~mm}$ bore diameter. Initially the cheek skin was sucked inward by applying 200 mbar of negative pressure, then held for $1.0 \mathrm{~s}$, and subsequently

Table 2. $\mathrm{IC}_{50}$ values for pentosidine formation in the selected plant extracts.

\begin{tabular}{|c|c|c|c|c|}
\hline Species & Scientific name & Family & Part of plant & $\mathrm{IC}_{50}(\mathrm{mg} / \mathrm{mL})$ \\
\hline Gambier & Uncaria gambir & Rubiaceae & Root & 0.17 \\
\hline Yerba mate & Ilex paraguayensis & Aquifoliaceae & Leaf & 0.18 \\
\hline Betel palm & Areca catechu & Arecaceae & Seed & 0.20 \\
\hline Evergreen wisteria & Millettia reticulata & Leguminosae & Tendril & 0.21 \\
\hline Onion & Allium сера & Liliaceae & Skin & 0.21 \\
\hline Lemon balm & Melissa officinalis & Lamiaceae & Leaf & 0.24 \\
\hline Rhubarb & Rheum officinale & Polygonaceae & Rhizome & 0.24 \\
\hline White birch & Betula platyphylla & Betulaceae & Bark & 0.24 \\
\hline Rosemary & Rosmarinus officinalis & Lamiaceae & Leaf & 0.26 \\
\hline Prince's feather & Polygoni orientalis & Polygonaceae & Seed & 0.26 \\
\hline Cat's whiskers & Orthosiphon stamineus & Lamiaceae & Leaf & 0.27 \\
\hline Thyme & Thymus vulgaris & Lamiaceae & Leaf and stem & 0.27 \\
\hline Arjuna & Terminalia arjuna & Combretaceae & Stem & 0.29 \\
\hline Bilberry & Vaccinium myrtillus & Ericaceae & Leaf & 0.29 \\
\hline Tea plant (green tea) & Camellia sinensis & Theaceae & Leaf & 0.29 \\
\hline Common tormentil & Potentilla erecta & Rosaceae & Root & 0.30 \\
\hline Witch hazel & Hamamelis virginiana & Hamamelidaceae & Bark & 0.30 \\
\hline AG & - & - & - & 0.30 \\
\hline Banaba & Lagerstroemia speciosa & Lythraceae & Leaf & 0.33 \\
\hline Guava & Psidium guajav & Myrtaceae & Leaf & 0.33 \\
\hline Tea plant (Nilgiri tea) & Camellia sinensis & Theaceae & Leaf & 0.33 \\
\hline Sweet tea & Rubus suavissimus & Rosaceae & Leaf & 0.35 \\
\hline
\end{tabular}


relaxed for $1.0 \mathrm{~s}$. The following elastic parameters were used for the evaluation of elasticity: gross elasticity (R2), net elasticity (R5), and the ratio of elastic recovery to the total deformation (R7). These parameters are known to be important indicators of skin elastic changes with aging (24). The forearm skin colors were measured using a CM-2600d to determine $a^{*}$ (red), $b^{*}$ (yellow), and L* (brightness) color values.

Hematological and biochemical measurements. Serum samples were prepared from blood collected after overnight fasting. The measurements of whole blood hematological parameters and serum biochemical parameters were carried out by Mitsubishi Chemical Medience Co. (Tokyo, Japan). Hemoglobin A1c (HbAlc) was measured using a DCA 2000 Analyzer (Bayer Diagnostics, Tarrytown, NY). LDL-cholesterol level was calculated from the levels of total cholesterol, HDL-cholesterol, and triglycerides using the Friedewald formula (25).

Table 3. Contents of polyphenols in LB leaf and the $\mathrm{IC}_{50}$ values for pentosidine formation.

\begin{tabular}{lcc}
\hline & $\begin{array}{c}\text { Contents in LB } \\
(\mathrm{mg} / \mathrm{g} \text { dry leaves })\end{array}$ & $\mathrm{IC}_{50}(\mathrm{mM})$ \\
\hline RA & 22.7 & 0.34 \\
Melitric acid A & 7.5 & 0.38 \\
Salvianic acid A & 3.3 & 0.16 \\
Caffeic acid & 0.6 & 0.48 \\
AG & - & 2.71 \\
\hline
\end{tabular}

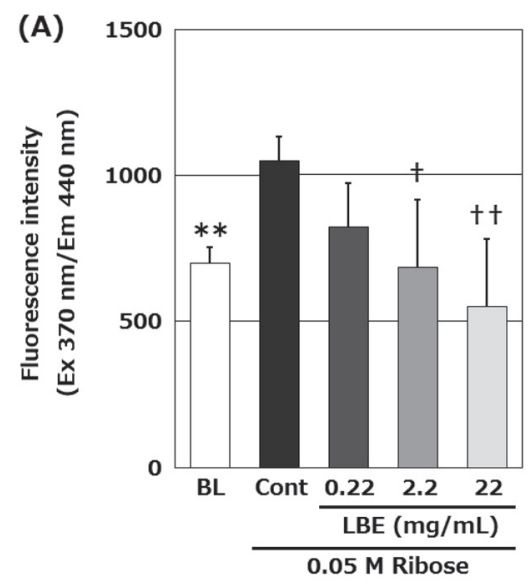

Statistical analysis. The data are presented as mean \pm SD. All data were analyzed with SAS preclinical package ver. 5.0 (SAS Institute Japan, Tokyo, Japan). In the in vitro study, Student's $t$-test or Welch's $t$-test was used after an F-test to compare the differences between two groups. Dunnett's test or Steel's test was adopted after Bartlett's test for multiple comparison among several groups. In the clinical trial, the following methods were employed to assess between-group differences. Non-normally distributed data certified by the ShapiroWilk test were analyzed using the Wilcoxon rank-sum test. Student's $t$-test or Welch's $t$-test was adopted for normally distributed data after an $F$-test. A paired $t$-test was applied for intra-group comparison before and after treatment. The frequency of adverse events was analyzed with Fisher's exact test. Correlation was evaluated by Pearson's correlation analysis. Two-sided $p$-values below 0.05 were considered to be statistically significant.

\section{RESULTS}

Screening of plant extracts with anti-glycation activity

Table 2 shows the $\mathrm{IC}_{50}$ values for pentosidine formation of the 21 candidates selected from 681 plant extracts. Among these, four species were Lamiaceae and 17 species exhibited higher activity than AG, an antiglycation agent. LB was selected from these candidate plants considering its safety, taste, stability of supply and adaptability to beverage.

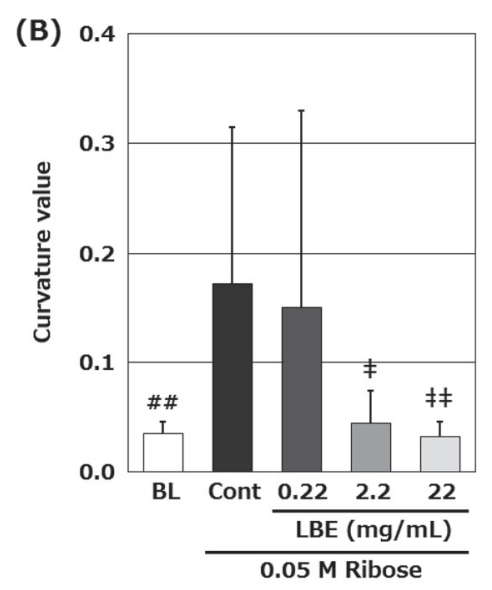

(C)
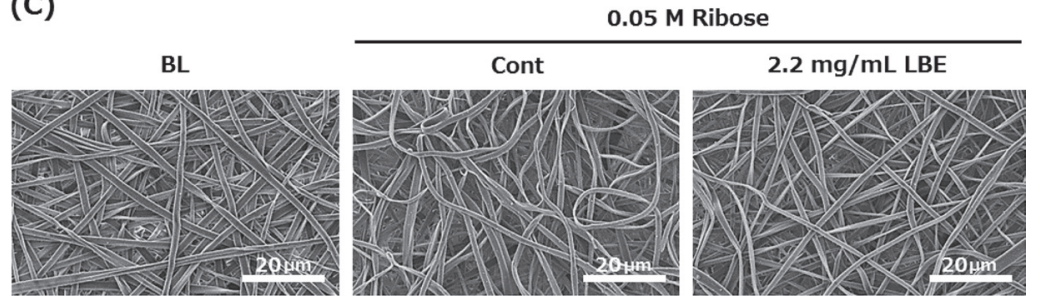

Fig. 1. The effects of LBE on glycation and the curvature of the fibrous structure of elastin fiber sheets. Elastin fiber sheets were incubated with $0.05 \mathrm{M}$ ribose in $100 \mathrm{~mm}$ phosphate buffer $(\mathrm{pH} 7.4)$ together with $\mathrm{LBE}$ at $37^{\circ} \mathrm{C}$ for 2 wk. BL: Blank (elastin fiber sheets incubated only in $100 \mathrm{~mm}$ phosphate buffer (pH 7.4)), Cont: Control (elastin fiber sheets incubated with only $0.05 \mathrm{M}$ ribose in $100 \mathrm{~mm}$ phosphate buffer (pH 7.4)). (A) Fluorescence (Ex $370 \mathrm{~nm} / \mathrm{Em} 440 \mathrm{~nm}$ ) intensity reflecting the amount of AGEs. Data show mean \pm SD $(n=4)$. (B) Curvature values. Data show mean \pm SD $(n=12)$. (C) SEM images. ${ }^{* *} p<0.01$ vs. Control (Student's $t$-test), ${ }^{\# \#} p<0.01$ vs. Control (Welch's $t$-test), ${ }^{\dagger} p<0.05,{ }^{\dagger \dagger} p<0.01$ vs. Control (Dunnett's test), ${ }^{\ddagger} p<0.05$, 

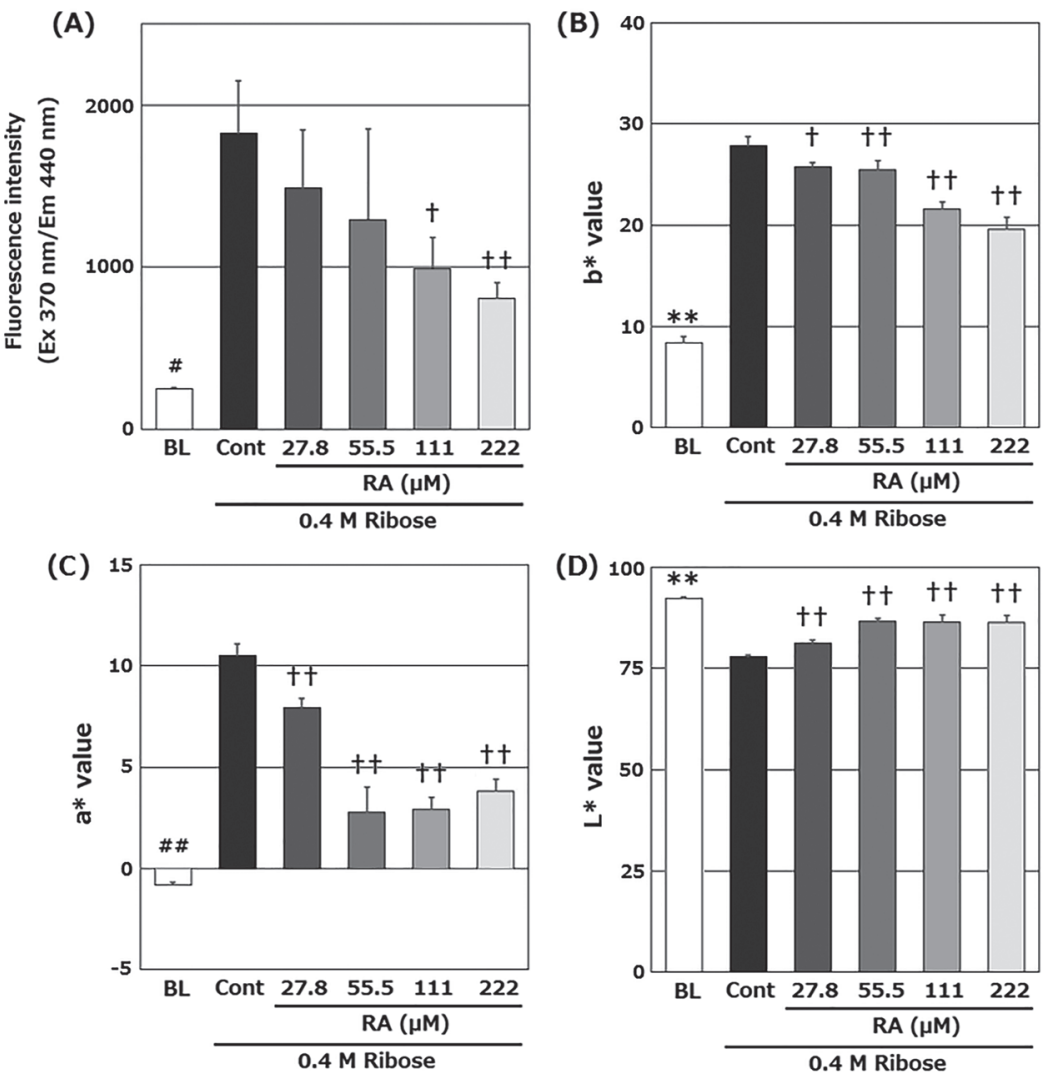

Fig. 2. The effects of RA on glycation and color values of collagen fiber sheets. (A) glycation, (B) b* value (yellow), (C) a* value (red), and (D) $\mathrm{L}^{*}$ value (brightness). Collagen sheets were incubated with $0.4 \mathrm{M}$ ribose in $100 \mathrm{~mm}$ phosphate buffer $\left(\mathrm{pH} 7.4\right.$ ) together with RA at $37^{\circ} \mathrm{C}$ for 1 wk. BL: Blank (collagen fiber sheets incubated only in $100 \mathrm{~mm}$ phosphate buffer (pH 7.4)), Cont: Control (collagen fiber sheets incubated with only $0.4 \mathrm{M}$ ribose in $100 \mathrm{~mm}$ phosphate buffer (pH 7.4)). Data show mean \pm SD $(n=3) .{ }^{* *} p<0.01$ vs. Control (Student's $t$-test), ${ }^{\#} p<0.05,{ }^{\# \#} p<0.01$ vs. Control (Welch's t-test), ${ }^{\dagger} p<0.05,{ }^{\dagger} p<0.01$ vs. Control (Dunnett's test).

\section{Identification and quantification of the active components in} LBE

LBE was fractionated to identify the active components, and high activity was detected in the polyphenol fraction. Separation of the major polyphenols in LBE was established using the HPLC system with a gradient method as described in "Materials and Methods." The major polyphenols were eluted at $4.5 \mathrm{~min}, 12.9 \mathrm{~min}$, $17.3 \mathrm{~min}$, and $22.0 \mathrm{~min}$, and were identified as salvianic acid A, caffeic acid, RA, and melitric acid A, respectively. Table 3 shows the contents of these polyphenols in $\mathrm{LB}$ leaf and their $\mathrm{IC}_{50}$ values for anti-glycation activity on a molar basis. All these polyphenols had higher activity than AG. Among them, RA was most abundant, suggesting that this polyphenol may be a major active component in LBE.

Effect on the fibrous structure of elastin fiber sheet

LBE dose-dependently inhibited the increase in fluorescence intensities reflecting the amount of AGEs (Fig. 1A) and the curved fibrous structures (Fig. 1B and C) induced by incubation with ribose. The ribose-induced increases in curvature were significantly suppressed by co-incubation with LBE at a final concentration of more than $2.2 \mathrm{mg} / \mathrm{mL}$ (Fig. 1B).

Effect on the coloration of collagen fiber sheet

As shown in Fig. 2, the fluorescence intensities and the $b^{*}$ (yellow) color values of collagen fiber sheets were increased by reaction with ribose, and these increases were suppressed by co-incubation with RA in a concentration-dependent manner. The $\mathrm{a}^{*}$ (red) color values were also increased by reaction with ribose, and these increases were suppressed by co-incubation with RA. The $L^{*}$ (brightness) color values were decreased by reaction with ribose, and these decreases were suppressed by co-incubation with RA.

Compliance and exclusion of subjects in the clinical trial

The sample intake rates were $100 \%$ in the Control group and $99.5 \%$ in the LB group. No subject took contraindicated drugs, and there was no between-group difference in the frequency of drug or alcohol intakes. Two subjects in the LB group were excluded from statistical analysis, because of health problems (chronic stomachache, tracheal foreign bodies) for more than $10 \mathrm{~d}$ during the intake period, for reasons other than sample intake. As shown in Table 4, there was no between-group difference in the revised baseline data except for $b^{*}$ value. Effect on arterial stiffness

As shown in Fig. 3, baPWV was reduced in the LB group $(-69.6 \pm 71.4 \mathrm{~cm} / \mathrm{s})$, whereas it was not changed in the Control group $(+15.0 \pm 73.5 \mathrm{~cm} / \mathrm{s})$ after intake of the designated sample tea. Accordingly a significant difference was detected in the change in baPWV between the two groups $(p=0.007)$. However, there were no significant between-group differences in the changes in systolic 
Table 4. Baseline data in clinical trial.

\begin{tabular}{lcc}
\hline & Control & LB \\
\hline $\begin{array}{l}\text { Number of subjects } \\
\text { (Male/female) }\end{array}$ & 14 & 12 \\
Age & $(7 / 7)$ & $(6 / 6)$ \\
Body weight (kg) & $44.8 \pm 9.6$ & $45.0 \pm 7.8$ \\
baPWV (cm/s) & $59.3 \pm 14.7$ & $59.1 \pm 8.6$ \\
SBP (mmHg) & $1,191 \pm 221$ & $1,227 \pm 209$ \\
DBP (mmHg) & $113 \pm 14$ & $118 \pm 14$ \\
Skin elasticity (cheek) & $71.8 \pm 10.2$ & $68.6 \pm 8.6$ \\
R2 & & \\
R5 & $0.70 \pm 0.06$ & $0.71 \pm 0.04$ \\
R7 & $0.74 \pm 0.09$ & $0.73 \pm 0.08$ \\
Skin color (forearm) & $0.52 \pm 0.06$ & $0.53 \pm 0.04$ \\
a* (red) color values & $6.43 \pm 1.71$ & $7.28 \pm 1.23$ \\
b* (yellow) color values & $17.1 \pm 1.9$ & $19.5 \pm 1.8 * *$ \\
L* (brightness) color values & $63.0 \pm 3.8$ & $64.9 \pm 3.8$ \\
\hline
\end{tabular}

Data show mean \pm SD. ${ }^{* *} p<0.01$ vs. Control (Student's $t$-test).

SBP: systolic blood pressure, DBP: diastolic blood pressure.

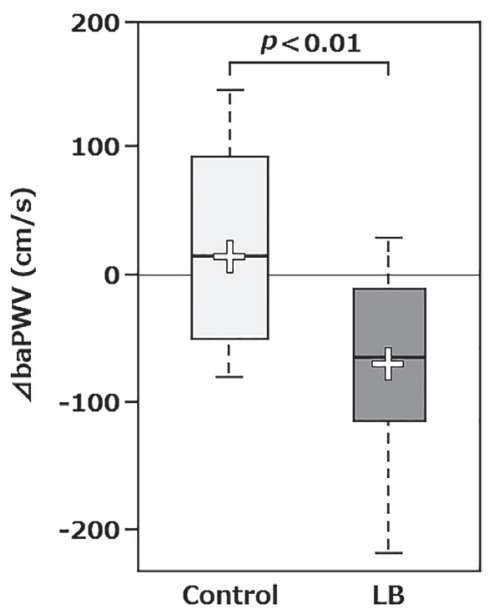

Fig. 3. Changes in baPWV during the intake period. Box plot presents median (bold horizontal lines) and mean values (plus signs), 25 th and 75 th percentiles (bottom and top of each box), and 10th and 90th percentiles (bottom and top of each whisker). Between-group differences were analyzed by Student's $t$-test.

blood pressure (Control group: $+0.71 \pm 6.41 \mathrm{mmHg}$, LB group: $-3.79 \pm 7.12 \mathrm{mmHg}$ ) or diastolic blood pressure (Control group: $-1.54 \pm 6.75 \mathrm{mmHg}$, LB group: $-1.92 \pm 2.47 \mathrm{mmHg}$ ). There was a significant positive correlation between the subject's age and baPWV at baseline $(R=0.693, p<0.001)$.

In the LB group, a significant negative correlation was found between the change in baPWV during the intake period and the baPWV value at baseline, but such correlation was not observed in the Control group (Fig. 4). Effect on the elasticity of cheek skin

When data for male and female subjects were analyzed together, there was no significant between-group difference in the change in elasticity of cheek skin during the intake period (Table 5). In a gender-stratified analysis, a significant between-group difference in R7

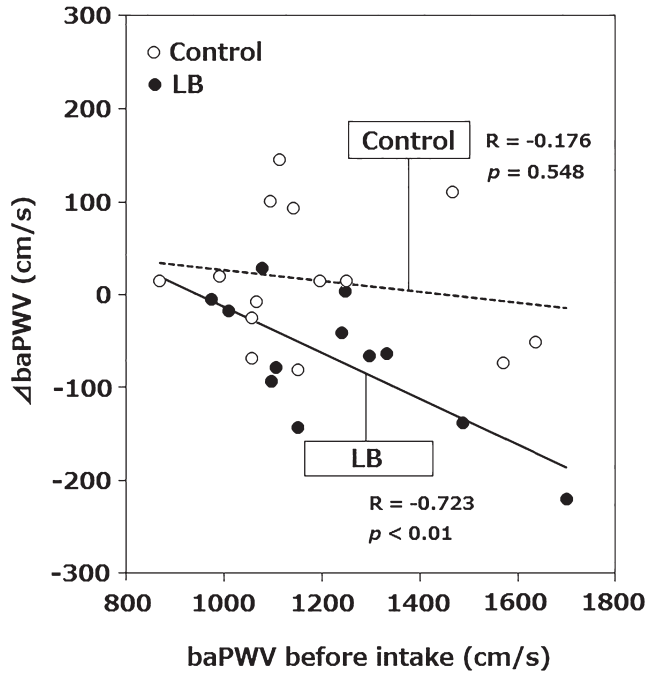

Fig. 4. Correlation between baPWV values at baseline and change in baPWV during the intake period. Correlation was evaluated by Pearson's correlation analysis.

Table 5. Changes in elastic parameters of cheek skin during the intake period.

\begin{tabular}{cccc}
\hline & Control & LB & $p$-value \\
\hline R2 & $-0.006 \pm 0.076$ & $-0.001 \pm 0.056$ & 0.835 \\
R5 & $-0.030 \pm 0.151$ & $-0.031 \pm 0.108$ & 0.975 \\
R7 & $-0.016 \pm 0.041$ & $-0.004 \pm 0.026$ & 0.382 \\
\hline
\end{tabular}

Data show mean \pm SD.

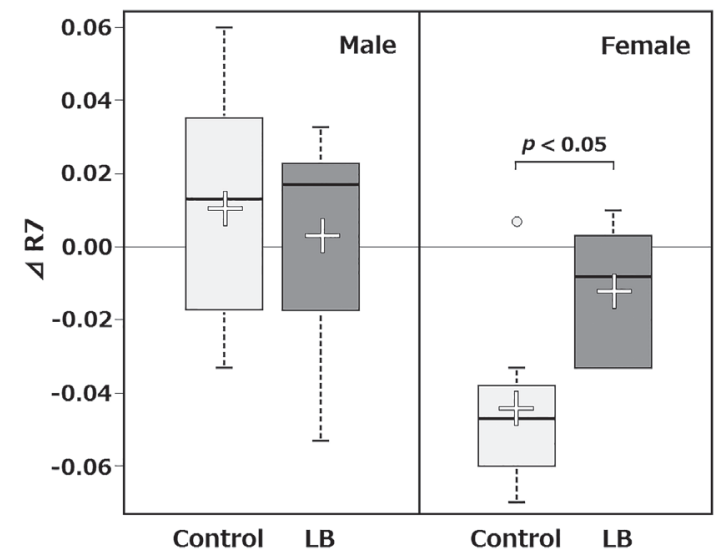

Fig. 5. Changes in the elastic value R7 of cheek skin during the intake period. Box plot presents median (bold horizontal lines) and mean values (plus signs), 25 th and 75 th percentiles (bottom and top of each box), and the 10th and 90th percentiles (bottom and top of each whisker). Between-group differences in male and female subjects were separately analyzed by Student's t-test.

value was found only in female subjects (Control group: $-0.044 \pm 0.025$, LB group: $-0.012 \pm 0.018, p=0.027$ ) (Fig. 5). No clear gender difference was observed in any of the other parameters measured in this trial. Effect on the color of forearm skin

During the intake period, both $\mathrm{a}^{*}$ (red) and $\mathrm{b}^{*}$ (yellow) 
(A)

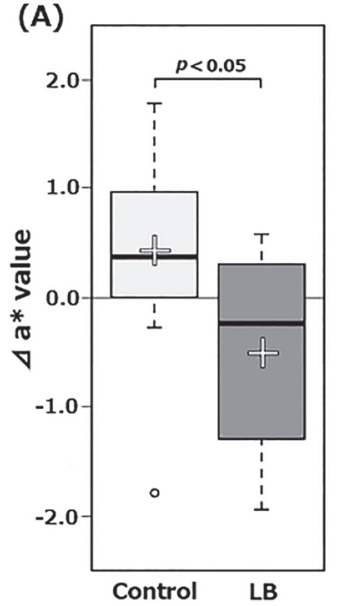

(B)

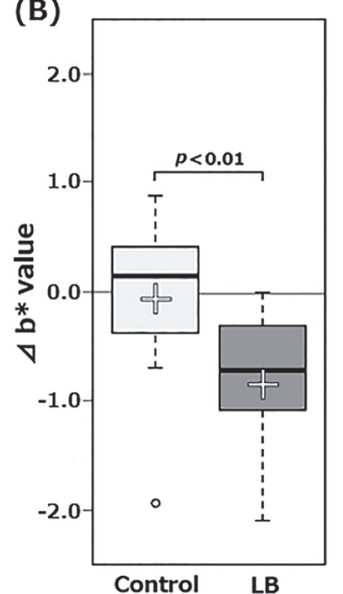

(C)

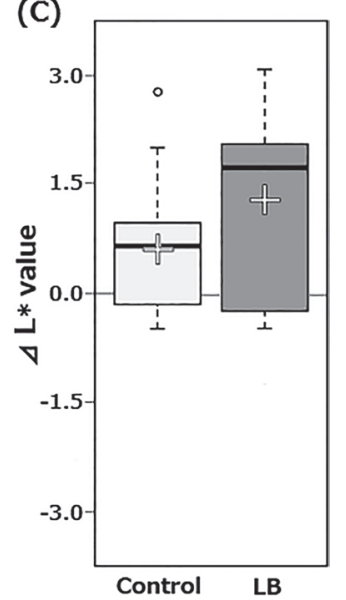

Fig. 6. Changes in color values of forearm skin during the intake period. (A) $a^{*}$ value (red), (B) $b^{*}$ value (yellow), and (C) $\mathrm{L}^{*}$ value (brightness). Box plot presents median (bold horizontal lines) and mean values (plus signs), 25th and 75th percentiles (bottom and top of each box), and 10th and 90th percentiles (bottom and top of each whisker). Between-group differences were analyzed by Student's $t$-test.

Table 6. Changes in hematological parameters during the intake period.

\begin{tabular}{lccccc}
\hline & \multicolumn{2}{c}{ Control } & & \multicolumn{2}{c}{ LB } \\
\cline { 2 - 3 } \cline { 5 - 6 } & Baseline & After 6 wk & & Baseline & After 6 wk \\
\hline White blood cell count $(/ \mu \mathrm{L})$ & $5,143 \pm 1,005$ & $5,421 \pm 1,174$ & & $4,967 \pm 1,477$ & $5,192 \pm 881$ \\
Red blood cell count $\left(\times 10^{4} / \mu \mathrm{L}\right)$ & $471 \pm 47$ & $472 \pm 52$ & & $462 \pm 39$ & $469 \pm 41$ \\
Platelet count $\left(\times 10^{4} / \mu \mathrm{L}\right)$ & $23.8 \pm 4.1$ & $24.6 \pm 4.9$ & & $21.8 \pm 5.0$ & $22.8 \pm 5.8$ \\
Hemoglobin $(\mathrm{g} / \mathrm{dL})$ & $14.4 \pm 1.5$ & $14.5 \pm 1.6$ & & $14.0 \pm 1.2$ & $14.3 \pm 1.3$ \\
Hematocrit $(\%)$ & $43.9 \pm 3.8$ & $43.8 \pm 4.2$ & & $42.6 \pm 3.3$ & $43.0 \pm 3.3$ \\
\hline
\end{tabular}

Data show mean \pm SD.

values in forearm skin were significantly reduced in the LB group, whereas they were not changed in the Control group (Fig. 6). As a result, significant between-group differences in these changes were observed $(p=0.017$ for $\mathrm{a}^{*}$ value, $p=0.008$ for $\mathrm{b}^{*}$ value) (Fig. 6). There was no between-group difference in the changes of $\mathrm{L}^{*}$ value. Adverse effects

There was no significant between-group difference in the frequencies of adverse events (Control group: 32/611, LB group: 35/614, $p=0.802$ ). Tables 6 and 7 show the hematological and biochemical parameters at baseline and after the 6 -wk intake period. As shown in Table 7, the serum glucose and uric acid levels after the intake period were significantly lower than those at baseline only in the Control group. However, the serum creatinine levels significantly decreased during the intake period in both groups. There were no significant changes in the other parameters.

\section{DISCUSSION}

Glycation-associated tissue damage is closely related to the onset of various diseases and aging phenomena. In this study, we aimed to find a potent anti-glycation food material and to verify its health benefits for glycation-associated tissue damage in a clinical trial.

This study demonstrated that the hot water extracts of some Lamiaceae plant leaves exhibited potent inhibi- tory activities against the formation of pentosidine (Table 2). These activities were stronger than those of AG (26) or green tea (27), which were reported to show anti-glycation effects in vivo, and LBE showed the highest activity among these Lamiaceae plants. RA, caffeic acid, salvianic acid A, and melitric acid A were identified as active components in LBE. In particular, RA is considered to be the major active component because of its high content in LB leaf. In addition to LB (28), RA (29), commonly contained in many Lamiaceae plants (30), has been reported to exhibit strong anti-glycation activity measured by fluorescence reflecting the amount of AGEs. Therefore RA and related polyphenols may contribute to the strong anti-glycation activity of Lamiaceae plants. These observations indicate that LBE and/ or RA may provide beneficial effects via anti-glycation activity in vivo.

As shown in Fig. 1, LBE dose-dependently suppressed the ribose-induced increases in AGE levels and the curved fibrous structures in elastin fiber sheets. Similar results were observed with $2.5 \mathrm{mM}$ RA corresponding to the concentration in $22 \mathrm{mg} / \mathrm{mL} \mathrm{LBE}$ (data not shown). Similarly, RA dose-dependently suppressed the riboseinduced increases in AGE levels and the collagen fiber sheet yellowing (Fig. 2). These results support previous findings that the glycation reaction is involved in the formation of fluorescent yellow pigments in lens proteins 
Table 7. Changes in blood biochemical parameters during the intake period.

\begin{tabular}{|c|c|c|c|c|}
\hline & \multicolumn{2}{|c|}{ Control } & \multicolumn{2}{|c|}{$\mathrm{LB}$} \\
\hline & Baseline & After $6 \mathrm{wk}$ & Baseline & After $6 \mathrm{wk}$ \\
\hline Glucose (mg/dL) & $94.9 \pm 9.2$ & $91.4 \pm 7.2^{*}$ & $93.3 \pm 15.3$ & $96.3 \pm 11.1$ \\
\hline $\operatorname{HbA1c}(\%)$ & $5.23 \pm 0.29$ & $5.14 \pm 0.3$ & $5.18 \pm 0.34$ & $5.18 \pm 0.35$ \\
\hline Insulin $(\mu \mathrm{U} / \mathrm{mL})$ & $6.81 \pm 6.51$ & $6.12 \pm 5.26$ & $5.19 \pm 3.47$ & $5.38 \pm 4.08$ \\
\hline Total cholesterol (mg/dL) & $201 \pm 26$ & $196 \pm 26$ & $188 \pm 33$ & $193 \pm 38$ \\
\hline HDL-cholesterol (mg/dL) & $65.3 \pm 14.1$ & $64.9 \pm 15.0$ & $66.9 \pm 18.5$ & $68.5 \pm 20.0$ \\
\hline LDL-cholesterol (mg/dL) & $121 \pm 28$ & $115 \pm 25$ & $106 \pm 23$ & $109 \pm 29$ \\
\hline Triglycerides $(\mathrm{mg} / \mathrm{dL})$ & $77.5 \pm 37.5$ & $81.5 \pm 28.5$ & $75.1 \pm 46.4$ & $77.6 \pm 45.6$ \\
\hline AST (IU/L) & $24.9 \pm 10.7$ & $24.7 \pm 7.0$ & $23.1 \pm 13.1$ & $26.3 \pm 12.3$ \\
\hline ALT (IU/L) & $28.5 \pm 25.9$ & $26.5 \pm 20.7$ & $29.9 \pm 46.0$ & $33.3 \pm 45.6$ \\
\hline$\gamma \mathrm{GTP}(\mathrm{IU} / \mathrm{L})$ & $28.8 \pm 14.8$ & $26.6 \pm 11.3$ & $32.8 \pm 31.7$ & $33.6 \pm 29.5$ \\
\hline Total bilirubin (mg/dL) & $0.95 \pm 0.34$ & $0.88 \pm 0.17$ & $1.02 \pm 0.43$ & $1.05 \pm 0.63$ \\
\hline Total protein $(\mathrm{g} / \mathrm{dL})$ & $7.51 \pm 0.49$ & $7.46 \pm 0.41$ & $7.29 \pm 0.34$ & $7.42 \pm 0.30$ \\
\hline Total albumin (g/dL) & $4.59 \pm 0.14$ & $4.52 \pm 0.12$ & $4.44 \pm 0.26$ & $4.52 \pm 0.30$ \\
\hline Urea nitrogen (mg/dL) & $11.8 \pm 2.7$ & $11.6 \pm 2.3$ & $12.5 \pm 2.4$ & $12.7 \pm 2.2$ \\
\hline Creatinine $(\mathrm{mg} / \mathrm{dL})$ & $0.75 \pm 0.11$ & $0.71 \pm 0.11^{* *}$ & $0.82 \pm 0.17$ & $0.79 \pm 0.16^{*}$ \\
\hline Uric acid $(\mathrm{mg} / \mathrm{dL})$ & $5.48 \pm 1.83$ & $5.06 \pm 1.49^{*}$ & $4.58 \pm 1.47$ & $4.48 \pm 1.35$ \\
\hline
\end{tabular}

Data show mean \pm SD. ${ }^{*} p<0.05,{ }^{* *} p<0.01$ vs. baseline (paired $t$-test).

AST: aspartate aminotransferase, ALT: alanine aminotransferase, $\gamma \mathrm{GTP}: \gamma$-glutamyl transpeptidase.

(16) and the curved fibrous structures in elastin fibers (15). Blood vessels and dermal tissues contain abundant collagen and elastin $(31,32)$. Previous studies have suggested that aging and the glycation reaction increase the stiffness of tissues such as arteries $(7,9)$ and skin $(10)$. Thus these findings indicate that arteries and skin are good targets for in vivo studies of LBE.

$\mathrm{LB}$ is reported to provide beneficial effects on cognitive function in clinical trials (18), psychological stress in an animal model (19), and suppression of oxidation in an in vitro study (33). However, there have been few studies of the effect of LB on arteries and skin. In our present clinical trial, conducted in healthy adult subjects, we found a reduction in baPWV compared with baseline only in the LB group, resulting in a significant difference in change in baPWV between the two groups (Fig. 3).

PWV is a widely used clinical index for arterial stiffness (34), and a high value indicates a high risk of cardiovascular disease (35), stroke (36), and cognitive decline (37). The results of a previous study of over 12,000 subjects also indicated that baPWV is positively correlated with age (38). These results also support our present observations of a strong positive correlation between age and initial baPWV values. Interestingly, only the LB group showed a significant negative correlation between the initial baPWV values and the change in baPWV during the intake period (Fig. 4). This suggests that LB tea may reduce arterial stiffness especially in subjects with high arterial stiffness.

In this trial, we also found a significant reduction in $\mathrm{a}^{*}$ (red) and $b^{*}$ (yellow) color values in the LB group compared with the Control group (Fig. 6). Because the skin color of the inner portion of the forearm is reported to hardly change from autumn to winter (39), these reductions are not considered to be due to seasonal environmental changes. RA, a major polyphenolic substance in
$\mathrm{LB}$, has been reported to have anti-inflammatory activity (40) that may affect $\mathrm{a}^{*}$ (red) value, and therefore the reduction of $\mathrm{a}^{*}$ value might be due to its anti-inflammatory effects. The $b^{*}$ value of mouse skin is reported to increase via glycation induced by glyoxal (41), and the increases in this value as well as intrinsic fluorescence of skin are interpreted as reflecting the accumulation of AGEs $(16,17)$. Therefore, the decrease in $b^{*}$ values is presumed to be due to the anti-glycation effects of the daily intake of LB tea. The brightness of skin has been reported to be associated with anti-oxidation $(42,43)$. In this clinical trial, LB tea did not affect the $\mathrm{L}^{*}$ value. This observation indicates that the involvement of anti-oxidation in the anti-glycation effect of LB tea may be small.

As shown in Fig. 5, the elasticity value R7 was greatly reduced in female subjects in the Control group, whereas there was almost no change in male subjects. Our clinical trial was carried out during the autumn and winter, with considerable changes in humidity and temperature. Since female skin is thin (44) and has a low moisture content (45) compared with male skin, the seasonal effects might be more severe in female subjects. By contrast, R7 values of the female subjects in the LB group hardly changed, indicating that LB tea suppressed the reduction of skin elasticity during the intake period in female subjects. Although the precise mechanism is unclear, we suppose that LB tea may prevent the seasonal deterioration of female skin properties via inhibition of glycation of skin proteins such as collagen and elastin.

In this clinical trial, we did not observe any differences in the frequencies of adverse events between the two groups or any LB group-specific abnormal changes in blood parameters (Tables 6 and 7). Significant change was observed only in serum creatinine level in the LB group, but this was within normal ranges and also observed in the Control group. A previous study dem- 
onstrated that LB caused no adverse events during longterm administration to patients with Alzheimer's disease (18). Moreover, LB has been consumed as a general medical herb for a long time in the West. Therefore, LB tea is considered as a safe foodstuff.

The urinary excretion rate of RA and its metabolites has been reported in a human trial with Perilla frutescens extract containing RA, and its value was $6.3 \%$ of total RA intake (46). Aside from RA, the following metabolites of RA were detected in human blood: methyl-RA, ferulic acid, and their sulfate and glucuronic acid conjugates. Although the metabolites mainly exist in conjugated forms in blood, it has been reported that conjugated polyphenols undergo deconjugation in tissues (47), which may lead to the anti-glycation effects of LB and/or RA in vivo.

Since the present clinical trial was carried out under an open-label design, there was a concern that behavior of subjects might change from psychological causes. To prevent this, the subjects were instructed to keep diaries of intake and lifestyle, and not to change their lifestyle such as dietary or exercise habits. The effects of behavioral bias were considered to be small, because there was no significant difference between the two groups in the compliance rate of intake, the frequency of drug or alcohol intakes (data not shown), or the high filling rate of diaries.

Limitations

Three limitations of this clinical trial should be considered. First, there was a lack of statistical power because of its small sample of participants. Hence, further studies with larger numbers of participants are necessary to clarify the beneficial effects of daily intake of LB tea on arteries and skin. The second limitation was its lack of detection of AGEs in arteries and skin. To clarify whether LB tea actually affects the AGE content in arteries and skin, clinical and/or animal studies are required using additional approaches such as the measurement of fluorescence caused by AGEs or the quantification of pentosidine in arteries and skin biopsy. The third limitation was study design. A double-blind placebo-controlled design was not adopted for this clinical trial, because the study was carried out as a first step of the research investigating the physiological activities of LB, and because an indistinguishable placebo was not available at the time.

Conclusion

The hot water extract of LB leaves is considered a safe and potent food material to provide health benefits with regard to glycation-associated tissue damage and symptoms such as increased arterial stiffness and decreased skin elasticity.

\section{Acknowledgments}

We thank Rika Ebina for technical assistance. We are also grateful to Dr. Tetsuji Hori and Dr. Fumiyasu Ishikawa for helpful advice.

\section{REFERENCES}

1) Monnier VM, Vishwanath V, Frank KE, Elmets CA, Dau- chot P, Kohn RR. 1986. Relation between complications of type I diabetes mellitus and collagen-linked fluorescence. N Engl J Med 314: 403-408.

2) Dyer DG, Dunn JA, Thorpe SR, Bailie KE, Lyons TJ, McCance DR, Baynes JW. 1993. Accumulation of Maillard reaction products in skin collagen in diabetes and aging. J Clin Invest 91: 2463-2469.

3) Stitt AW, Li YM, Gardiner TA, Bucala R, Archer DB, Vlassara H. 1997. Advanced glycation end products (AGEs) co-localize with AGE receptors in the retinal vasculature of diabetic and of AGE-infused rats. Am J Pathol 150: $523-531$.

4) Mitsuhashi T, Nakayama H, Itoh T, Kuwajima S, Aoki S, Atsumi T, Koike T. 1993. Immunochemical detection of advanced glycation end products in renal cortex from STZ-induced diabetic rat. Diabetes 42: 826-832.

5) Monnier VM, Stevens VJ, Cerami A. 1979. Nonenzymatic glycosylation, sulfhydryl oxidation, and aggregation of lens proteins in experimental sugar cataracts. J Exp Med 150: 1098-1107.

6) Cantini C, Kieffer P, Corman B, Limiñana P, Atkinson J, Lartaud-Idjouadiene I. 2001. Aminoguanidine and aortic wall mechanics, structure, and composition in aged rats. Hypertension 38: 943-948.

7) Sims TJ, Rasmussen LM, Oxlund H, Bailey AJ. 1996. The role of glycation cross-links in diabetic vascular stiffening. Diabetologia 39: 946-951.

8) Sasaki N, Fukatsu R, Tsuzuki K, Hayashi Y, Yoshida T, Fujii N, Koike T, Wakayama I, Yanagihara R, Garruto R, Amano N, Makita Z. 1998. Advanced glycation end products in Alzheimer's disease and other neurodegenerative diseases. Am J Pathol 153: 1149-1155.

9) De Angelis L, Millasseau SC, Smith A, Viberti G, Jones RH, Ritter JM, Chowienczyk PJ. 2004. Sex differences in age-related stiffening of the aorta in subjects with type 2 diabetes. Hypertension 44: 67-71.

10) Takema Y, Yorimoto Y, Kawai M, Imokawa G. 1994. Age-related changes in the elastic properties and thickness of human facial skin. Br J Dermatol 131: 641-648.

11) Seirafi H, Farsinejad K, Firooz A, Davoudi SM, Robati RM, Hoseini MS, Ehsani AH, Sadr B. 2009. Biophysical characteristics of skin in diabetes: a controlled study. J Eur Acad Dermatol Venereol 23: 146-149.

12) Sell DR, Monnier VM. 1989. Structure elucidation of a senescence cross-link from human extracellular matrix. J Biol Chem 264: 21597-21602.

13) Bank RA, Bayliss MT, Lafeber FP, Maroudas A, Tekoppele JM. 1998. Ageing and zonal variation in post-translational modification of collagen in normal human articular cartilage. The age-related increase in non-enzymatic glycation affects biomechanical properties of cartilage. Biochem J 330: 345-351.

14) Reddy GK. 2004. Cross-linking in collagen by nonenzymatic glycation increases the matrix stiffness in rabbit achilles tendon. Exp Diabesity Res 5: 143-153.

15) Yoshinaga E, Kawada A, Ono K, Fujimoto E, Wachi H, Harumiya S, Nagai R, Tajima S. 2012. N(ع)(carboxymethyl)lysine modification of elastin alters its biological properties: implications for the accumulation of abnormal elastic fibers in actinic elastosis. J Invest Dermatol 132: 315-323.

16) Monnier VM, Cerami A. 1981. Nonenzymatic browning in vivo: possible process for aging of long-lived proteins. Science 21 1: 491-493.

17) Ohshima H, Oyobikawa M, Tada A, Maeda T, Takiwaki 
H, Itoh M, Kanto H. 2009. Melanin and facial skin fluorescence as markers of yellowish discoloration with aging. Skin Res Technol 15: 496-502.

18) Akhondzadeh S, Noroozian M, Mohammadi M, Ohadinia S, Jamshidi AH, Khani M. 2003. Melissa officinalis extract in the treatment of patients with mild to moderate Alzheimer's disease: a double blind, randomised, placebo controlled trial. J Neurol Neurosurg Psychiatry 74: 863-866.

19) Taiwo AE, Leite FB, Lucena GM, Barros M, Silveira D, Silva MV, Ferreira VM. 2012. Anxiolytic and antidepressant-like effects of Melissa officinalis (lemon balm) extract in rats: Influence of administration and gender. Indian J Pharmacol 44: 189-192.

20) Pauli GF, Gödecke T, Jaki BU, Lankin DC. 2012. Quantitative ${ }^{1} \mathrm{H}$ NMR. Development and potential of an analytical method: an update. J Nat Prod 27: 834-851.

21) Yamaguchi F, Ariga T, Yoshimura Y, Nakazawa H. 2000. Antioxidative and anti-glycation activity of garcinol from Garcinia indica fruit rind. J Agric Food Chem 48: 180-185.

22) Bullitt E, Gerig G, Pizer SM, Lin W, Aylward SR. 2003. Measuring tortuosity of the intracerebral vasculature from MRA images. IEEE Trans Med Imaging 22: 1163-1171.

23) Iwasa K, Torii H. 1962. A colorimetric determination of tea tannin with ferrous tartrate. Study of Tea 26: 87-91 (in Japanese).

24) Ryu HS, Joo YH, Kim SO, Park KC, Youn SW. 2008. Influence of age and regional differences on skin elasticity as measured by the Cutometer. Skin Res Technol 14: 354-358.

25) Friedewald WT, Levy RI, Fredrickson DS. 1972. Estimation of the concentration of low-density lipoprotein cholesterol in plasma, without use of the preparative ultracentrifuge. Clin Chem 18: 499-502.

26) Li YM, Steffes M, Donnelly T, Liu C, Fuh H, Basgen J, Bucala R, Vlassara H. 1996. Prevention of cardiovascular and renal pathology of aging by the advanced glycation inhibitor aminoguanidine. Proc Natl Acad Sci USA 93: 3902-3907.

27) Babu PV, Sabitha KE, Shyamaladevi CS. 2006. Therapeutic effect of green tea extract on advanced glycation and cross-linking of collagen in the aorta of streptozotocin diabetic rats. Clin Exp Pharmacol Physiol 33: 351-357.

28) Mehran M, Sima K, Sorour M, Mansoureh S. 2011. Inhibitory effects of lemon balm (Melissa officinalis, L.) extract on the formation of advanced glycation end products. Food Chem 129: 267-271.

29) Zhang X, Hu S, Chen F, Wang M. 2014. Treatment of proteins with dietary polyphenols lowers the formation of AGEs and AGE-induced toxicity. Food Funct 5: 2656-2661.

30) Kivilompolo M, Hyötyläinen T. 2007. Comprehensive two-dimensional liquid chromatography in analysis of Lamiaceae herbs: characterisation and quantification of antioxidant phenolic acids. J Chromatogr A 1145: 155-164.

31) Gomez EC, Berman B. 1985. The aging skin. Clin Geriatr Med 1: 285-305.

32) Lowry OH, Gilligan DR, Katersky EM. 1941. The determination of collagen and elastin in tissues, with results obtained in various normal tissues from different species. J Biol Chem 139: 795-804.

33) Luño V, Gil L, Olaciregui M, Jerez RA, de Blas I, Hozbor
F. 2015. Antioxidant effect of lemon balm (Melissa officinalis) and mate tea (Ilex paraguensys) on quality, lipid peroxidation and DNA oxidation of cryopreserved boar epididymal spermatozoa. Andrologia 47: 1004-1011.

34) Mattace-Raso FU, van der Cammen TJ, Hofman A, van Popele NM, Bos ML, Schalekamp MA, Asmar R, Reneman RS, Hoeks AP, Breteler MM, Witteman JC. 2006. Arterial stiffness and risk of coronary heart disease and stroke: the Rotterdam Study. Circulation 113: 657-663.

35) Vlachopoulos C, Aznaouridis K, Terentes-Printzios D, Ioakeimidis N, Stefanadis C. 2012. Prediction of cardiovascular events and all-cause mortality with brachialankle elasticity index: a systematic review and metaanalysis. Hypertension 60: 556-562.

36) Laurent S, Boutouyrie P, Asmar R, Gautier I, Laloux B, Guize L, Ducimetiere P, Benetos A. 2001. Aortic stiffness is an independent predictor of all-cause and cardiovascular mortality in hypertensive patients. Hypertension 37: 1236-1241.

37) Waldstein SR, Rice SC, Thayer JF, Najjar SS, Scuteri A, Zonderman AB. 2008. Pulse pressure and pulse wave velocity are related to cognitive decline in the Baltimore Longitudinal Study of Aging. Hypertension 51: 99-104.

38) Tomiyama H, Yamashina A, Arai T, Hirose K, Koji Y, Chikamori T, Hori S, Yamamoto Y, Doba N, Hinohara S. 2006. Influences of age and gender on results of noninvasive brachial-ankle pulse wave velocity measurement - a survey of 12517 subjects. Atherosclerosis 166: 303-309.

39) Kawai S, Satou T, Traji K. 1987. Study on the change in shades of skin color with seasons. J Color Sci Assoc Jpn 11: 56-57 (in Japanese).

40) Osakabe N, Takano H, Sanbongi C, Yasuda A, Yanagisawa R, Inoue K, Yoshikawa T. 2004. Anti-inflammatory and anti-allergic effect of rosmarinic acid (RA); inhibition of seasonal allergic rhinoconjunctivitis (SAR) and its mechanism. Biofactors 21: 127-131.

41) Yokota M, Tokudome Y. 2015. Permeation of hydrophilic molecules across glycated skin is differentially regulated by the stratum corneum and epidermis-dermis. Biol Pharm Bull 38: 1383-1388.

42) Kim SB, Jo YH, Liu Q, Ahn JH, Hong IP, Han SM, Hwang BY, Lee MK. 2015. Optimization of extraction condition of bee pollen using response surface methodology: Correlation between anti-melanogenesis, antioxidant activity, and phenolic content. Molecules 20: 19764-19774.

43) Ya W, Chun-Meng Z, Tao G, Yi-Lin Z, Ping Z. 2015. Preliminary screening of 44 plant extracts for anti-tyrosinase and antioxidant activities. Pak J Pharm Sci 28: $1737-1744$.

44) Shuster S, Black MM, McVitie E. 1975. The influence of age and sex on skin thickness, skin collagen and density. Br J Dermatol 93: 639-643.

45) Mayrovitz HN, Carson S, Luis M. 2010. Male-female differences in forearm skin tissue dielectric constant. Clin Physiol Funct Imaging 30: 328-332.

46) Baba S, Osakabe N, Natsume M, Yasuda A, Muto Y, Hiyoshi K, Takano H, Yoshikawa T, Terao J. 2005. Absorption, metabolism, degradation and urinary excretion of rosmarinic acid after intake of Perilla frutescens extract in humans. Eur J Nutr 44: 1-9.

47) Perez-Vizcaino F, Duarte J, Santos-Buelga C. 2012. The flavonoid paradox: conjugation and deconjugation as key steps for the biological activity of flavonoids. J Sci Food Agric 92: 1822-1825. 